\title{
TOXICIDAD DE CEPAS DE Aspergillus flavus AISLADAS DEL MAIZ
}

\section{Toxicity of Aspergillus flavus strains isolated from corn.}

\author{
Nepote, M.C.* , Piontelli, L. E. **, Saubois, A.* \\ *Universidad Nacional del Litoral,Facultad de Ingeniería Química, \\ Cátedra de Microbiología, Santiago del Estero 2829. 3000 Santa Fe, Argentina. \\ **Universidad de Valparaíso, Escuela de Medicina, Cátedra de Micología, \\ Casilla 92V. Valparaiso, Chile.
}

Palabras clave Aspergillus flavus, capacidad toxigénica, maíz. Key words:Aspergillus flavus, toxigenic capacity, corn.

\section{RESUMEN}

En muestras de granos de maiz de la zona centro norte de la Provincia de Santa Fe, Argentina, se seleccionaron 10 cepas de Aspergillus flavus, para estudiar sus caracteristicas morfotaxonómicas y toxicogénicas. Para los esnsayos taxonómicos, se efectuaron observaciones macro y microscópicas de los cultivos puros en CYA y $M E A$, mientras los ensayos de toxicidad en elmedio YES, registrandose la producción de aflatoxina en algunas cepas a los 7, 14 y 21 dias de incubación.

Mediante el empleo de cromatografia en capa fina, se determinó la presencia de aflatoxinas con los estandares correspondientes $(B 1, B 2, G 1, G 2)$. Los resultados obtenidos en base a la morfología y la producción de aflatoxinas, permitió afirmar que la totalidad de las cepas ensayadas, pertenecian a la especie A.flavus Link:Fr.

Dos cepas produjeron aflatoxinas $B 1$ y B2, a los 14 y 21 dias de incubación. Solo 1 de ellas produjo cantidades significativas de ambas toxinas, pero ninguna produjo aflatoxinas $G$.

Se destaca el valor quimiotaxonómico de los estudios de toxigenicidad, para la identificación a nivel de especie dentro de la Sección Flavi.

\section{INTRODUCCION}

Las aflatoxinas son metabolitos secundarios producidos por algunas cepas de Aspergillus flavus Link:Fr. y por la mayoría de las cepas de A.parasiticus Speare.

A.flavus, parece adaptarse al desarrollo activo en las partes aéreas de las plantas y es la especie productora dominante del maíz. Más del $90 \%$ de los aislamientos productores de aflatoxinas, provenientes del maiz, corresponden a esta especie (1). Dentro del taxon, se ha demostrado la existencia de cepas productoras y no productoras de toxinas. En diferentes regiones del mundo,

\section{SUMMARY}

Ten strains of Aspergillus flavus were selected from corn grain samples collected at the central and northern areas of the Provincia de Santa Fe, Argentina in order to study their morphotaxonomic and toxigenic characteristics. Taxonomic assays were $c$ arried out through macro and microscopic observations of pure cultures in CYA and $M E A$, whereas toxicity tests were performed in the $Y E S$ medium resulting in aflatoxin production in some strains after a 7,14 anả 21 days incubation.

The presence of aflatoxins with their corresponding standards (B1, B2, G1, G2) could be determined by using thin layer cromatography. Final results, which were based on morphology and the production of aflatoxins, made it possible to confirm that every strain tested belonged to the genus A. flavus Link:Fr.

Two strains produced aflatoxins B1 and B2 after 14 and 21 days of incubation. Only one of them produced a significant number of both toxins yet none produced aflatoxins $G$.

It is remarkable the chemotaxonomic value of studies on toxigenicity for the identification at a species level within the Flavi Section.

ambos tipos de cepas presentan características diferenciales en cultivo, correspondientes a patrones regionales definidos (2). Murakami (3), Murakami et al.,(4), Christensen, (5) y posteriormente Klich \& Pitt (2), consideran que la rugosidad de las paredes conidiales, color de los cultivos viejos y diámetro de los conidios, constituyen caracteres estables, útiles para la identificación de las especies del grupo, estableciendo una clara distinción entre los productores dè aflatoxinas conocidos actualmente (A.flavus y A.parasiticus).En U.S.A., A. flavus, está comunmente relacionado con la contaminación del maíz y es responsable de la producción de aflatoxinas $\mathrm{B}^{1} \mathrm{y} \mathrm{B}^{2}$, en tanto que $A$. parasiticus, está asociado a la contaminación del maní y es 
productor de aflatoxinas B1, B2, G1 y G2 (6). Los distintos aislamientos varían ampliamente en cuanto a su habilidad para producir aflatoxinas ya sea en el campo o en cultivos de laboratorio. Existe una importante correlación entre la producción de aflatoxinas en cultivos de laboratorio y la ha bilidad de un determinado aislamiento para contaminar los tejidos vegetales vivos en pre y post-cosecha. Diversos medios de cultivos han sido evaluados para llevar a cabo los ensayos de capacidad toxigénica, desde la inoculación de cultivos en campos experimentales, hasta la utilización de medios sintéticos en el laboratorio $(7,8,12)$. Un medio que ha dado excelentes resultados para evaluar la producción de aflatoxinas es el medio YES, líquido o agarizado (9). La simplicidad de su composiciónyla ausencia de interferencias químicas en los cromatogramas de los extractos fúngicos obtenidos a partir de los cultivos en este medio, hacen posible su empleo para llevar a cabo un rápido ensayo de un gran número de aislamientos en un tiempo relativamente corto. Si bien los cultivos en medios naturales, como los elaborados con granos de cereales, brindan mayor semejanza con la realidad, existe en los granos un gran número de compuestos, principalmente lípidos y sustancias lipofilicas, que son extraídas conjuntamente con las toxinas y enmascaran su detección final por métodos físicos-químicos, elevando los limites de detección (10).Lapresencia de $A$. flavus en muestras sospechosas, no siempre constituye una evidencia de la presencia de toxina en la misma. Ello ha sido demostrado en diferentes áreas de cultivo del maiz, principalmente en USA (6). Sin embargo, si los estudios de identificación y confirmación del hongo son acompañados de las correspondientes pruebas de evaluación de toxigenicidad de los aislamientos, ello resulta de gran utilidad para establecer el riesgo que tales materiales significan para la salud humana y animal.

Los objetivos del presente trabajo fueron: estudiar en cepas de $A_{\text {fflavus }}$ provenientes de los granos analizados, las características morfotaxonómicas, la capacidad toxicogénica y su variación in vitro en el tiempo.

\section{MATERIALES Y METODOS}

Se estudiaron 10 cepas seleccionadas al azar de $A$. flavus, obtenidas de 30 muestras de granos de maiz de la zona centro-norte de la Provincia de Santa Fe, Argentina, cosecha 1992/93.Los aislamientos se desarrollaron en estrías (5-7 días), en PDA, a $25^{\circ} \mathrm{C}$, hasta obtener buena esporulación. Se realizaron suspensiones conidiales agregando $10 \mathrm{ml}$ de agua destilada estéril a cada cultivo en estría. Dichas suspensiones se emplearon como inóculo para los estudios taxónomicos $\mathrm{y}$ de toxigenicidad.

Observaciones taxonómicas. Se examinó el desarrollo macroscópico de las colonias mediante empleo de lupa estereoscópica, registrándose las características de textura, zonificación y diámetro de las mismas; color del micelio y reverso de las colonias, presencia y color del exudado. Se efectuaron mediciones microscópicas de las vesículas y de los conidios, rugosidad de los mismos, registrándose el porcentaje de cabezas conidiales biseriadas. Las mediciones microscópicas se efectuaron con microscopio de campo claro, a partir de los cultivos puros desarrollados en los medios agar Czpek-extracto de levadura (CYA) y agar extracto de malta (MEA), a los 5, 10 y 20 días de incubación, a $25^{\circ} \mathrm{C}$, bajo luz difusa. Para ello se empleó la metología propuesta por Klich \& Pitt (2). Se examinó además la producción de esclerocios en cultivos puros y en los granos de maíz cultivados sobre PDA directamente, en las condiciones mencionadas anteriormente.

Amálisis de aflatoxinas. Alícuotas de $0,1 \mathrm{ml}$ de las suspensiones de conidios fueron inoculadas en medio YES ( $2 \%$ de extracto de levadura $+20 \%$ de sacarosa), sin agarizar (9). Los cultivos se incubaron a $28^{\circ} \mathrm{C}$, en posición inclinada, para favorecer la oxigenación durante 7, 14 y 21 días (7). Las toxinas se extrajeron con $5 \mathrm{ml} \mathrm{de} \mathrm{CHCL}_{3}$, agitando 1 minuto a baja velocidad. Luego de filtrar, se separó y evaporó la capa clorofórmica. Lós extractos secos se reconstituyeron con $200 \mathrm{ml}$ de benceno-acetonitrilo (98:2). La presencia de aflatoxinas se determinó mediante cromatografia en capa fina (TLC), sembrando conjuntamente diferentes concentraciones de estándares de aflatoxinas B1, B2, G1 y G2. Se efectuó cuantificación visual mediante comparación con los estandares de referencia. Se empleó $\mathrm{CHCl}_{3}$ - acetona (90:10) como solvente para la corrida. Las toxinas se confirmaron mediante TLC bidimensional y rociado con $\mathrm{H}_{2} \mathrm{SO}_{4}$ al $30 \%$ (11).

\section{RESULTADOS Y DISCUSIÓN}

. Los resultados obtenidos de las observaciones taxonómicas y la determinación de aflatoxina, se observan en la Tabla 1 y Tabla 2, respectivamente. Todas las cepas ensayadas se confirmaron como A.flavus Link: $\mathrm{Fr}$, resultando las características y mediciones microscópicas coincidentes con las de M.Christensen (6) y M.A.Klich \& J.I.Pitt (2), para la especie. Se destacan los siguientes resultados del examen: conidios lisos o ligeramente rugosos con promedio de 2,73$5,43 \mu \mathrm{m}$; diámetro de las vesículas de 24 y $44 \mu \mathrm{m} ; 25-30 \%$ de cabezas biseriadas; color de los cultivos verde amarillento a oliva claro,persistente a los 20 días de incubación. Ocho aislamientos produjeron esclerocios en los granos enteros del maíz sobre la superficie de placas de Petri con PDA, CYA y MEA, conservándose esta propiedad hasta la tercera transferencia. Ninguna de las cepas produjo aflatoxinas a los 7 días de incubación. Dos produjeron aflatoxinas B1 y B2 a los 14 y 21 días de incubación. Sólo una produjo cantidades detectables de ambas toxinas (Tabla 2). Esta cepa fue aislada de una muestra de maiz donde habian sido detectadas ambas aflatoxinas. La otra cepa produjo sólo trazas de ambas toxinas y provenía de una muestra de maíz donde sólo se había 
Tabla 1

Principales características macro y micromorfológicas de los aislamientos de Aspergillus flavus

\begin{tabular}{|ccccc|}
\hline $\begin{array}{c}\text { Aislamiento } \\
\mathrm{N}^{\circ}\end{array}$ & $\begin{array}{c}\text { Diámetro } \\
\text { prom. de } \\
\text { vesícula } \mu \mathrm{m} \\
\text { (a) }\end{array}$ & $\begin{array}{c}\text { Rugosidad } \\
\text { conidios }\end{array}$ & $\begin{array}{c}\text { \% Cabezas } \\
\text { biseriadas }\end{array}$ & $\begin{array}{c}\text { Presencia } \\
\text { esclerocios } \\
\text { (b) }\end{array}$ \\
\hline $1 \mathrm{AF}$ & 25 & 1 & 30 & + \\
$2 \mathrm{AF}$ & 28 & 1 & 25 & + \\
$5 \mathrm{AF}$ & 44 & 1 & 30 & - \\
$6 \mathrm{AF}$ & 24 & 1 & 26 & + \\
$8 \mathrm{AF}$ & 40 & 1 & 26 & - \\
$16 \mathrm{AF}$ & 25 & 1 & 25 & + \\
$21 \mathrm{AF}$ & 36 & 1 & 28 & + \\
$28 \mathrm{AF}$ & 25 & 1 & 25 & + \\
$34 \mathrm{AF}$ & 28 & 1 & 30 & + \\
$35 \mathrm{AF}$ & 24 & 1 & 26 & + \\
\hline
\end{tabular}

a: Escala adoptada por M.A. Klich \& Pitt (6)

$\mathbf{1}=$ Lisos a levemente rugosos $\mathbf{2}=$ Rugosos $\mathbf{3}=$ Muy rugosos.

b: Presente en granos enteros sobre PDA y en cultivo puro sobre CYA y PDA.

Tabla 2

Producción de aflatoxinas en medio YES a diferentes tiempos de incubación.

\begin{tabular}{|ccccccc|}
\hline & \multicolumn{7}{c|}{ Concentración de aflatoxina $(\mu \mathrm{g} / \mathrm{ml})$} \\
Aislamiento & \multicolumn{2}{c}{7 dias } & 14 dias & \multicolumn{2}{c|}{21 dias } \\
$N^{\circ}$ & B1 & B2 & B1 & B2 & B1 & B2 \\
\hline $1 \mathrm{AF}$ & - & - & tr & tr & tr & tr \\
$2 \mathrm{AF}$ & - & - & - & - & - & - \\
$3 \mathrm{AF}$ & - & - & - & - & - & - \\
$6 \mathrm{AF}$ & - & - & 0,4 & 0,075 & 0,5 & 0,18 \\
$8 \mathrm{AF}$ & - & - & - & - & - & - \\
$16 \mathrm{AF}$ & - & - & - & - & - & - \\
$21 \mathrm{AF}$ & - & - & - & - & - & - \\
$28 \mathrm{AF}$ & - & - & - & - & - & - \\
$34 \mathrm{AF}$ & - & - & - & - & - & - \\
$35 \mathrm{AF}$ & - & - & - & - & - & - \\
\hline
\end{tabular}

B1: aflatoxina B1 B2: aflatoxina B2 tr: trazas

detectado aflatoxina B1 (12). Coincidentemente, ni en los granos, ni en los cultivos de $\boldsymbol{A}$. flavus in vitro fueron detectadas aflatoxinas G. Diferentes autores aconsejan realizar el ensayo de toxigenicidad en medio YES a diferentes tiempos de incubación $(2,11)$. Debido a los aumentos registrados en los niveles de aflatoxina B2 a los 21 días respecto de los 14 días, se recomienda incluir el ensayo a los 21 días de incubación.
La variación observada puede implicar una modificación en la relación cuantitativa de aflatoxina $\mathrm{B} 1 /$ aflatoxina B2-(5,3 y 2,7 para 14 y 21 días de incubación, respectivamente)en etapas posteriores a la cosecha, a pesar que diversos factores pueden modificar la expresión de toxicidad de la especie, principalmente aquellos determinantes del complejo ecosistema post-cosecha $(1,3,14)$.

\section{CONCLUSIONES}

Taxonomía: No se observaron diferencias significativas en la rugosidad de los conidios, ni en el tamaño de los mismos para las distintas cepas. Asi mismo, se puede concluir que las características macro y microscópicas estudias coinciden con las observadas por Klich \& Pitt para la especie A.flavus en otras regiones geográficas (2).

Producción de aflatoxinas: Los resultados fueron coincidentes con los observados en estudios previos sobre la incidencia de aflatoxinas $B$ en el maíz de la región $(12,13)$, donde se demuestra que las cepas de A.flavus aisladas en el presente estudio provenían de muestras de granos contaminados en forma natural con aflatoxinas B (12). Las pruebas de toxigenicidad efectuadas, resultaron de valor quimiotaxonómico en la identificación a nivel del especie dentro de la Sección Flavi. Inversamente, las características taxonómicas pueden emplearse como herramienta complementaria en los estudios de incidencia de aflatoxinas. La utilización de perfiles de metabolitos secundarios tóxicos, característicos y estables, puede extenderse al estudio taxonómico de otras especies toxigénicas. Ello ha sido propuesto por Frisvad para diferentes especies de Penicillium (8).

\section{REFERENCIAS}

1.-Moss, M.O.(1989).Mycotoxins of Aspergillus and other filamentous fung. Journal Appl. Bacteriol., Symposium Supplement, 69S-81S.

2.-Klich ,M.A.\& Pitt,J. (1985). The theory and practice of distinguishing of the Aspergillus flavus Group. In: Advances in Penicillium and Aspergillus Systematics, R. A. Samson \& J. Pitt, (Eds.), N. York Plenum Press, N.Y., pp. 211-220.

3.-Murakami,H. (1971).Clasification of the koji mould. Journal Gen. Appl. Microbiol., 17: 281-309.

4.-Murakami, H.; Hayashi, K; Ushyjima, S. (1982). Useful key characters separating three Aspergillus taxa: A. sojae, A.parasiticus and A. toxicarius. Journal Gen. Appl. Microbiol., 28: 55-60.

5.-Christensen, M.A. (1981). A synoptic key and evaluation of species in the Aspergillus flavus Group". Mycologia, 73: 1056-1084.

6.-Christensen, C.M. (1991). Fungi and seed quality. In: Handbook of Applied Mycology. Vol. 3: Foods and Feeds, D.K. Arora, K.G. Mukerji and E.H. Marth, (Eds.), Marcel Dekker Inc., N. Y., pp. 99-120. 
7.-Mujica, M.T.; Umansky, G.A.;Bracalenti B.J. (1983). Estudio comparativo de dos métodos rápidos para la detección de hongos toxicogénicos. Revista Latinoamericana de Microbiologia, 25 : 193196.

8.-Filtenborg, O. \& Frisvad, J.C. (1980). A simple screeningmethod for toxigenic moulds in pure culture. Lebensm. wiss. Technol. 13:128-130.

9.-Draughon, F.A.; Elahi, M.E.; Churchville, D.C. ;West, D.R. (1987). Pesticide inhibition of aflatoxin and zearalenone production in corn and in culture. Tennessee Farm and Home Science 23: 3-7.

10.-Lacey, J. (1989). Pre- and post-harvest ecology of fungi causing spoilage of foods and other stored products. Journal Appl. Bacteriol. Symposium Supplement: 11S-25S.

11.-Wei, D.-L.; Chen, W.-L.; Wei, R.-D.; Jong, S.-C. (1984). Identity of aflatoxins producing ability of Aspergillus reference cultures: H. Kurata and Y. Ueno (Eds.), Kodansha Ltd., Tokyo Elservier, Amsterdam, pp. 87-97.
12.Nepote, M.C.\& Saubois, A. (1994) Incidencia de Aspergillus flavus y aflatoxinas en maíz de la Provincia de Santa Fe. Libro de Actas, VI Congreso Argentino de Ciencia y Tecnología de Alimentos, Organizado por la Asociación Argentina de Tecnólogos Alimentarios (AATA) y el Programa de Tecnología de Alimentos de la Universidad de Buenos Aires (PROTAL). Buenos Aires, Argentina.

13.-Nepote, M.C.;Saubois, A.; Beccaria, A.; Basílico, J.C. (1994). Grado de contaminación por aflatoxinas y zearalenona en maíz y subproductos procesados en un molino harinero de la ciudad de Santa Fe (Argentina). Revista Iberoamericana de Micología 11: 37-39.

14.Cotty, P.J. (1981) Virulence and cultural characteristics of two Aspergillus flavus strains pathogenic on cotton. Phytopathology 79:808-814. 